\title{
Tuning $\mathrm{Al}_{2} \mathrm{O}_{3}$ crystallinity under supercritical fluid conditions: effect on sintering
}

\author{
C. Bousquet, C. Elissalde, C. Aymonier, M. Maglione, F. Cansell, J.M. Heintz* \\ Institut de Chimie de la Matière Condensée de Bordeaux ICMCB-CNRS and ENSCPB, \\ Université Bordeaux I, 87, Av. Dr A.Schweitzer, \\ 33608 PESSAC Cedex (France)
}

* Corresponding author. Email: heintz@icmcb-bordeaux.cnrs.fr, Tel: 0540006257

\begin{abstract}
Supercritical fluids have been used to prepare alumina powders. This versatile technique allows tuning the crystallinity of the obtained alumina by a simple modification of the fluid nature. Using $\mathrm{CO}_{2}$ /Ethanol or $\mathrm{H}_{2} \mathrm{O}$ /Ethanol, respectively amorphous or boehmite alumina can be successfully obtained. The sintering paths of the two types of powders differ greatly. It has been correlated to their grain morphology and crystalline state. It is shown that the alumina elaborated in $\mathrm{CO}_{2} /$ Ethanol shows a significant decrease of the $\gamma$ $\mathrm{Al}_{2} \mathrm{O}_{3} \rightarrow \alpha-\mathrm{Al}_{2} \mathrm{O}_{3}$ transition temperature resulting in a lower densification temperature.
\end{abstract}

Keywords: $\mathrm{Al}_{2} \mathrm{O}_{3}(D)$, Sintering (A), Powders-chemical preparation (A), Supercritical fluids 


\section{Introduction}

Alumina is the most widely used oxide ceramic material. It can be obtained in many metastable states $(\gamma, \delta, \theta, \kappa, \varepsilon, \eta, \chi)$ which lead upon thermal treatment to the thermodynamically stable $\alpha-\mathrm{Al}_{2} \mathrm{O}_{3}$ phase. ${ }^{1}$ This stable corundum structure is obtained at high temperature and is used in a wide range of ceramic and refractory applications. ${ }^{2} \mathrm{~A}$ key interest for cost reduction is to soften the sintering conditions required to obtain interesting alumina-based ceramics. Global sintering processes involve different oxidehydroxides of aluminium as starting materials, which lead first to various metastable alumina through dehydration/dehydroxylation mechanisms. ${ }^{3}$ Then, phase transitions involving eventually microstructural rearrangements lead to corundum formation. ${ }^{4}$ Once corundum crystallized, the final material densification occurs.

Improvement of corundum densification is expected by lowering the transition temperature. Many strategies have thus been probed. Legros et al have summarized in a recent review paper the main efficient processes used during the sintering stages. ${ }^{5}$ Seeds of alpha alumina and other doping agents have been commonly introduced into transition alumina before sintering in order to enhance kinetics of transition. ${ }^{6,7}$ Although the transition temperature actually decreased, it is difficult to obtain monolithic pieces by this first route. In the case of the use of doping elements like $\mathrm{Y}, \mathrm{Zr}, \mathrm{Mg}$, formation of parasite phases is hardly avoided. ${ }^{8}$ Another strategy is to use pressure sintering but it requires heavy equipments which do not allow an efficient control of the sample geometry. ${ }^{4,9}$

Besides, some research groups focussed their work on optimising the synthesis routes of starting alumina powders. Several wet chemical methods lead to diverse oxide/hydroxides of aluminium, crystallized or not. Using sol-gel method, Sharma et al. have obtained gels with different crystallinities according to $\mathrm{pH}$ conditions. As a result, 
the transition temperature was lowered from 1170 to $930^{\circ} \mathrm{C} .{ }^{11}$ However, this route required long reaction times. A recent report by Hernandez et al. showed the influence of synthesis route for obtaining dense $\mathrm{TiO}_{2}$-doped alumina ceramics. ${ }^{12}$ Using coprecipitation, $\gamma$-alumina was also synthesized and the resulting ceramics, obtained after calcinations at $1125^{\circ} \mathrm{C}$, were made of $\theta$-alumina. Pechini and sol-gel processes lead to amorphous alumina as starting alumina powder. Transformation in $\alpha$-alumina is fully achieved after a similar thermal treatment. These two examples highlight the role of crystallinity as a key factor for the sintering process.

As an alternative synthesis method, supercritical fluid route is a versatile method allowing the control of powder properties (size, morphology, crystallinity...). ${ }^{13,14}$ For example, Araï et al. have obtained boehmite with different particle size and shape. ${ }^{15}$ Danchevskaya et al. have obtained directly $\alpha-\mathrm{Al}_{2} \mathrm{O}_{3} \cdot{ }^{16}$ These works were both performed in supercritical water. Here, we propose to optimise the reaction media in order to tune the alumina crystallinity. Our objective is to investigate the influence of the powder crystallinity on the microstructure of the final ceramic. Such an approach is based on the understanding of the phase transition mechanism during sintering.

\section{Experimental procedure}

\subsection{Sample preparation}

Two different routes were used to prepare $\alpha$-alumina (Fig. 1). In both cases, the metal precursor used was aluminium acetylacetonate (99\%, Aldrich). The chemical transformation of $\mathrm{Al}\left(\mathrm{C}_{5} \mathrm{H}_{7} \mathrm{O}_{2}\right)_{3}$ in water/ethanol results in the formation of boehmite, as already observed in supercritical water ${ }^{15}$ whereas the thermal decomposition of 
$\mathrm{Al}\left(\mathrm{C}_{5} \mathrm{H}_{7} \mathrm{O}_{2}\right)_{3}$ in supercritical $\mathrm{CO}_{2} /$ ethanol leads to the formation of amorphous alumina. $^{17}$

The experimental set-up is described in Fig. 2. The precursor and liquid solvents are added into the high pressure and high temperature stirred vessel reactor (volume of 60 $\left.\mathrm{cm}^{3}\right)$. The reactor is closed, filled with carbon dioxide in the case of $\mathrm{CO}_{2} /$ ethanol and reaches the operating conditions indicated in Fig.1. In these experimental conditions, the $\mathrm{CO}_{2}$ /ethanol mixture is supercritical $\left(\mathrm{P}_{\mathrm{c}}(\text { mixture })=14.5 \mathrm{MPa}, \mathrm{T}_{\mathrm{c}}(\text { mixture })=92^{\circ} \mathrm{C}\right)^{18}$ whereas the water/ethanol mixture is subcritical $\left(\mathrm{P}_{\mathrm{c}}(\right.$ mixture $)=11 \mathrm{MPa}, \mathrm{T}_{\mathrm{c}}($ mixture $)=$ $\left.315^{\circ} \mathrm{C}\right)^{19}$

The last step of the process differs for the two systems. For water/ethanol, the assynthesized powder is collected in the initial mixture after vessel cooling. It is then filtered. For $\mathrm{CO}_{2} /$ ethanol, pure supercritical $\mathrm{CO}_{2}$ flows through the reactor to remove ethanol and organic residues from aluminium precursor. The powder is then dry and can be recovered without any additional filtering step.

The two different powders were then cold pressed and sintered in order to obtain ceramics. The heating schedule was made of two steps : $680^{\circ} \mathrm{C}$ during $1 \mathrm{~h}$ and $1200^{\circ} \mathrm{C}$ during 4 hours, with a heating rate of $300^{\circ} \mathrm{C} / \mathrm{h}$,

\subsection{Characterization methods}

Transmission electron microscopy (TEM) imaging was performed using a Philips Tecnai equipped with a Megaview II camera. The specimen for the TEM was prepared by depositing a few droplets of a dilute nanoparticles suspension in ethanol onto a carbon-coated copper grid, followed by drying under ambient conditions. 
The ceramics microstructure was observed using a scanning electron microscope (SEM) JEOL JSM 6360A. A thin platinum coating was deposited on the fracture surface prior to observation.

Thermal behaviour of powders was investigated by thermal gravimetric analysis (TGA), dilatometry (TMA) and X-ray diffractometry (XRD).

Thermal gravimetric analysis was performed using SETARAM microbalance mtb 108.

NETZSCH 402 ED differential dilatometer was used to record the length change of samples with a heating rate of $5^{\circ} \mathrm{C} / \mathrm{min}$.

Phase analysis was conducted using a panalytical X'Pert MPD diffractometer with Bragg Brentano geometry and $\mathrm{Cu} K_{\alpha}$ radiation $(\lambda=1.5418 \AA)$. It was equipped with a high temperature room (Anton Paar HTK16).

\section{Results and discussion}

\subsection{XRD analysis}

The X-ray patterns of the powders obtained by the two routes are shown in Fig. 3. The powder formed in the water/ethanol medium is a well-crystallized boehmite phase $(\mathrm{AlO}(\mathrm{OH}))$ whereas $\mathrm{CO}_{2} /$ ethanol solvent leads to an amorphous powder.

The structural evolution of the powder with temperature has been highlighted thanks to temperature X-ray diffractions (Fig. 4).

Boehmite from water/ethanol system transforms into $\alpha$-alumina via three transition alumina: $\delta, \gamma$ and $\theta$. The mixture of $\delta$-and $\gamma$-alumina, observed at $500^{\circ} \mathrm{C}$, is transformed 
into a mixture of $\gamma$ - and $\theta$ - alumina, as shown by the diffractogram recorded at $1080^{\circ} \mathrm{C}$ in (Fig. 4(a)).

Amorphous powder obtained in the $\mathrm{CO}_{2}$ /ethanol system is also transformed in $\alpha$ alumina but with only one intermediate phase observed at $850^{\circ} \mathrm{C}$ which is the $\gamma$-alumina phase (Fig. 4b).

Both boehmite and amorphous powders are transformed into $\alpha$-alumina via the same $\gamma$-alumina intermediate. The transformation into $\alpha$-alumina is complete at $1080^{\circ} \mathrm{C}$ when the initial powder is amorphous whereas $\theta$-alumina still remains with $\alpha$-alumina up to $1215^{\circ} \mathrm{C}$ for the boehmite powder.

\subsection{TMA/TGA analysis}

Dimensional and mass changes of pellets during the heating steps have been used to determine the sintering paths (Fig. 5). Both techniques have been correlated to X-ray diffraction results. In fact, the thermal behaviour of the two powders differs greatly depending on their crystalline state.

The pellet made of boehmite (synthesized in water/ethanol medium) follows a twostep process. Further to dehydration/dehydroxylation phenomena that take place under $500^{\circ} \mathrm{C}$, a part of boehmite transforms into $\delta$-alumina and $\gamma$-alumina. Dehydration and dehydroxylation mechanisms, already reported in the literature ${ }^{3}$, are pointed out by the TGA measurement, which shows a $15 \%$ weight loss at $470^{\circ} \mathrm{C}$. The second shrinkage occurs between $800^{\circ} \mathrm{C}$ to $1200^{\circ} \mathrm{C}$. It is due to the network contraction that corresponds to the evolution of the $\delta$ and $\gamma$-alumina powders towards a mixture of $\theta$ - and $\gamma$-alumina. It finally transforms into $\alpha$-alumina above $1150^{\circ} \mathrm{C}$ as shown by $\mathrm{X}$-ray analysis. 
The pellet of amorphous alumina, obtained in the $\mathrm{CO}_{2}$ /ethanol supercritical medium, undergoes, at low temperature, two first shrinkages due to the departure of organic residues of the aluminium precursor. Weight losses observed in TGA measurement for the same temperature range confirm this hypothesis. Then, still in agreement with XRD analyses, an important peak close to $800^{\circ} \mathrm{C}$ confirms the crystallization of amorphous alumina into $\gamma$-alumina. A last shrinkage indicates that $\gamma$-alumina already transforms into $\alpha$-alumina since $1000^{\circ} \mathrm{C}$ and that the transition is complete at $1080^{\circ} \mathrm{C}$.

In Fig. 6, an enlargement of the shrinkage rate curve in the temperature range of the $\gamma-\mathrm{Al}_{2} \mathrm{O}_{3} \rightarrow \alpha-\mathrm{Al}_{2} \mathrm{O}_{3}$ transition allows to compare the onset of this transition according to the fluid nature. The transition of the powder synthesized in water/ethanol actually starts at $1150^{\circ} \mathrm{C}$ whereas the transition of the powder obtained from $\mathrm{CO}_{2} /$ ethanol starts at $1000^{\circ} \mathrm{C}$.

\subsection{Powder morphology and microstructure}

Fig. 7 shows the final microstructures of the ceramics obtained after sintering of the two powders at $1200^{\circ} \mathrm{C}$. Boehmite, obtained in water/ethanol, leads to a porous ceramic with a vermicular microstructure composed of submicrometers grains. The amorphous powder synthesized in supercritical $\mathrm{CO}_{2}$ /ethanol gives a ceramic made of large and dense grains. 


\subsection{Sintering paths}

Thanks to thermal and X-ray diffraction characterizations, a sintering path is proposed in Fig. 8, which explains the different behaviours according to the crystallinity of the starting powders.

In the case of boehmite, the initial powder is made of very small crystallites (nm size range as determined by TEM). Such a powder is very difficult to compact and leads to a porous green sample. It has been shown that the densification of such loose packing powder requires very high temperatures and also rearrangements during sintering stages. ${ }^{19}$ In fact, the densification of this boehmite sample is limited by the loose packing but also by the coexistence of different transition alumina (Fig. 8(a)). Boehmite transforms first into $\gamma$ and $\delta$ which transforms itself into $\theta$ above $800^{\circ} \mathrm{C}$. First, this transformation delays the $\gamma-\mathrm{Al}_{2} \mathrm{O}_{3} \rightarrow \alpha-\mathrm{Al}_{2} \mathrm{O}_{3}$ transition to higher temperature $\left(1150^{\circ} \mathrm{C}\right)$. In that temperature range sintering already takes place which makes the material more rigid and necessarily limits intergranular rearrangement. Second, the occurrence of residual $\theta$ grains can impede the rearrangement stage required to reach a good densification as it is commonly observed during the densification of two-phase composite materials. ${ }^{20}$ As a result, boehmite sintering leads to a porous ceramic with a vermicular microstructure.

In the case of amorphous alumina, the starting powder contains larger grains ( $\mu \mathrm{m}$ size range as determined by TEM) and a more important organic part due to the precursor decomposition (nearly $50 \%$ in weight observed in TGA). In the early stage of sintering, a first interparticle rearrangement is associated with organics elimination (peak close to $400^{\circ} \mathrm{C}$ on TMA). The $\alpha$ crystallisation follows very closely the $\gamma$ one 
$\left(800^{\circ} \mathrm{C}\right)$ and occurs at lower temperature $\left(1000^{\circ} \mathrm{C}\right)$ than usually observed ${ }^{10}$. In this temperature range, the ceramic is sufficiently "soft" to allow intergranular movements. A second grains rearrangement could accompany the $\gamma-\mathrm{Al}_{2} \mathrm{O}_{3} \rightarrow \alpha-\mathrm{Al}_{2} \mathrm{O}_{3}$ transformation. This transformation is already finished at $1080^{\circ} \mathrm{C}$; as the densification is then high, grain growth is favoured until $1200^{\circ} \mathrm{C}$ (Fig. 8(b)).

The amorphous character of the powder elaborated in $\mathrm{CO}_{2}$ /ethanol allows decreasing the temperature of the $\gamma-\mathrm{Al}_{2} \mathrm{O}_{3} \rightarrow \alpha-\mathrm{Al}_{2} \mathrm{O}_{3}$ transition of about $150^{\circ} \mathrm{C}$ and it leads to a denser ceramic than the one made of powder crystallized in water/ethanol (boehmite).

\section{Conclusions}

Supercritical fluids route allows controlling the elaboration of two types of $\alpha$-alumina precursors by a simple modification of reaction medium. Boehmite in water/ethanol and amorphous alumina in $\mathrm{CO}_{2}$ /ethanol are thus obtained. The influence of the starting powder crystallinity on the sintering properties has then been studied. Sintering paths have been proposed for each starting alumina. Both powders lead to the thermodynamically stable $\alpha-\mathrm{Al}_{2} \mathrm{O}_{3}$ phase through the same transition alumina: $\gamma-\mathrm{Al}_{2} \mathrm{O}_{3}$. The alumina elaborated in $\mathrm{CO}_{2}$ /ethanol shows interesting sintering properties and in particular it presents a significant improvement in the lowering of the temperature of the $\gamma-\mathrm{Al}_{2} \mathrm{O}_{3} \rightarrow \alpha-\mathrm{Al}_{2} \mathrm{O}_{3}$ transition $\left(150^{\circ} \mathrm{C}\right)$. 


\section{Acknowledgements}

Financial support from the French National Center for Scientific Research (CNRS), the National Research Agency (ANR), the European Community in the frame of the "FAME" network of excellence and the "Region Aquitaine" are gratefully acknowledged. We thank Dominique Denux for TMA, Philippe Dagault for TGA and Eric Lebraud for XRD measurements.

\section{References}

1. Levin, I., Brandon, D., Metastable Alumina Polymorphs: Crystal Structures and transition sequences, J. Am. Ceram. Soc., 1998, 81[8], 1995-2012.

2. Hidalgo, H., Dépôt chimique en phase vapeur de couches minces d'alumine dans une postdécharge micro-onde, PhD manuscript, 2003.

3. Mishra, D, Anand, S., Panda, R.K., Das, R.P., Hydrothermal preparation and characterization of boehmites, Mater. Lett., 2000, 42, 38-45.

4. Bowen, P., Carry, C., From powders to sintered pieces: forming, transformations and sintering of nanostructured ceramic oxides, Powder Technology, 2002, 128, 248-255.

5. Legros, C., Herbst, F., Lartigue-Korinek, S., Carry, C., Bowen, P., Sintering of nanostructured alumina: influence of various parameters, La revue de métallurgie, 2002, 1073-1080.

6. Scott Nordahl, C., Messing, G. L., Sintering of $\alpha-\mathrm{Al}_{2} \mathrm{O}_{3}$-seeded nanocrystalline $\gamma-\mathrm{Al}_{2} \mathrm{O}_{3}$ powders, J. Eur. Ceram. Soc., 2002, 22, 415-422.

7. Bowen, P., Carry, C., From Powders to sintered pieces: forming, transformations and sintering of nanostructured ceramic oxides, Powder Technology, 2002, 128, 248-255.

8. Lartigue-Korinek, S., Legros, C., Carry, C., Herbst, F., Titanium effect on phase transformation and sintering behavior of transition alumina, J. Eur. Ceram. Soc., 2006, 26, 2219-2230.

9. Mostaghaci \& al, J. brit. Ceram. Soc., 84[6], 203-206 (1985)

10. Mishra, R. S., Lesher, C. E., Mukherjee, A. K., High-Pressure sintering of nanocrystalline $\gamma$ $\mathrm{Al}_{2} \mathrm{O}_{3}$, J. Am.. Ceram. Soc., 1996, 79[11], 2989-2992.

11. Sharma, P.K., Varadan, V. V., Varadan, V.K., A critical role of $\mathrm{pH}$ in the colloidal synthesis and phase transformation of nano size $\alpha-\mathrm{Al}_{2} \mathrm{O}_{3}$ with high surface area, J. Eur. Ceram. Soc., 2003, 23, 659-666.

12. Hernandez, T., Bautista, M. C., The role of the synthesis route to obtain densified $\mathrm{TiO}_{2}$-doped alumina ceramics, J. Eur. Ceram. Soc., 2005, 25, 663-672.

13. Aymonier, C., Cansell, F., Supercritical fluid techniques, Ann. Chem. Sci. Mat., 2006, 31(3), $317-$ 337.

14. Aymonier, C., Loppinet-Serani, A., Reveron, H., Garrabos, Y., Cansell, F., Review of supercritical fluids in inorganic materials science, J. Supercrit. Fluids, 2006, 38 (2), 242-251.

15. Hakuta, Y., Ura, H., Hayashi, H.,Arai, K., Effects of hydrothermal synthetic conditions on the particle size of $\gamma-\mathrm{AlO}(\mathrm{OH})$ in sub and supercritical water using a flow reaction system, Mater. Chem. Phys., 2005, 93, 466-472.

16. Panasyuk, G. P., Danchevskaya, M. N., Belan, V. N., Voroshilov, I. L., Ivakin, D. Y., Phenomenology of corundum crystal formation in supercritical water fluid, J. Phys. Cond. Matter, 2004, 16, S1187-S1196.

17. Aymonier, C., Elissalde, C., Reveron, H., Weill, F., Maglione, M., Cansell, F., Supercritical fluid technology of nanoparticles coating for new ceramic materials, J. Nanosci. Nanotech., 2005, 5, 980-983.

18. Hernandez-Garduza, O., Garcia-Sanchez, F., Neau, E., Rogalski, M., Equation of state associated with activity coefficient models to predict low and high pressure vapor-liquid equilibria, Chem. Eng. J., 2000, 79, 87-101.

19. Legros, C., Carry, C., Bowen, P., Hoffmann, H., Sintering of a transition alumina: effects of phase transformation, powder characteristics and thermal cycle, J. Eur. Ceram. Soc., 1999, 19, 19671978.

20. German, R.M., Sintering and practice, J. Wiley \& Sons, New York, 1996, pp. 178-225. 


\section{Figure Captions}

Fig. 1. Flow diagrams for the two routes used to produce $\alpha$-alumina in sub- and supercritical fluid media (ts : residence time, $\mathrm{pc}$ : critical pressure, Tc : critical temperature).

Fig. 2. High pressure, high temperature stirred reactor for material synthesis in supercritical fluids. P and T are pressure and temperature controllers, respectively.

Fig. 3. X-ray patterns of the powders according to the fluid nature used for the powder synthesis.

Fig. 4. Structural evolution with temperature of powders synthesized in (a) water/ethanol ( $\square$ boehmite, $\circ \gamma$ alumina, $\bullet \delta$-alumina, $\bullet \theta$-alumina and $* \alpha$-alumina) and (b) $\mathrm{CO}_{2}$ /ethanol. ( $\circ \gamma$-alumina, $* \alpha$-alumina).

Fig. 5. TMA (shrinkage rate) and TGA for powders obtained in a) water/ethanol b) $\mathrm{CO}_{2} /$ ethanol. TGA ordinate axis is on the left side of the figure. The derivative of the shrinkage ordinate axis is on the right side of the figure.

Fig. 6. Shrinkage rate in the temperature range of the $\gamma \rightarrow \alpha$ transition for the two powders.

Fig. 7. SEM micrographs of alumina ceramics sintered during $4 \mathrm{~h}$ at $1200^{\circ} \mathrm{C}$.

Fig. 8. Proposed sintering paths for (a) boehmite obtained in water/ethanol and (b) amorphous alumina synthesised in $\mathrm{CO}_{2}$ /ethanol. ${ }^{19}$ 


\section{$\mathrm{H}_{2} \mathrm{O}$ /Ethanol medium $\mathrm{CO}_{2}$ /Ethanol medium}

$50 / 50$ in mass

(pc mixture $=14.5 \mathrm{MPa}$,

Tc mixture $=92^{\circ} \mathrm{C}$ )

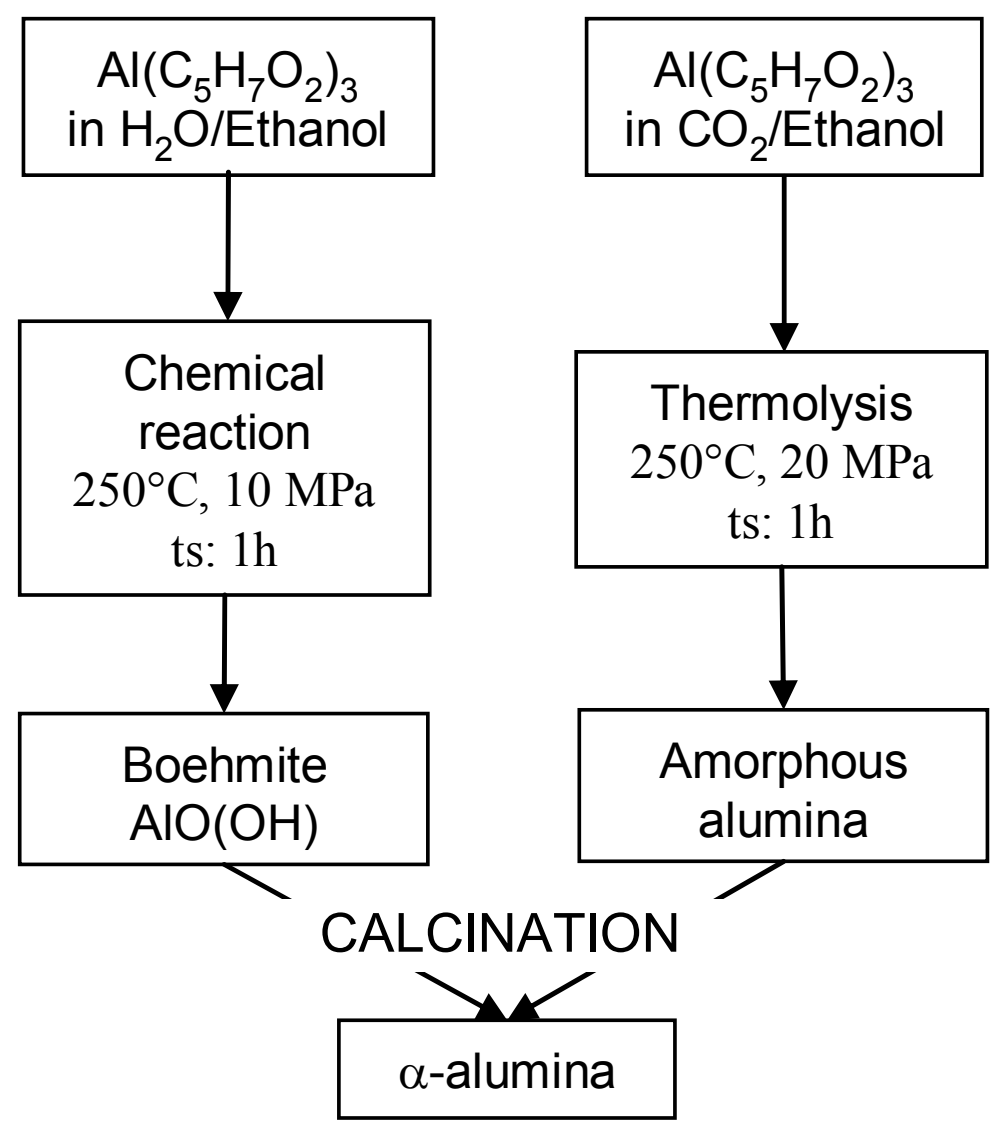

$80 / 20$ in mass

(pc mixture $=11 \mathrm{MPa}$,

Tc mixture $=315^{\circ} \mathrm{C}$ )

Fig. 1. Flow diagrams for the two routes used to produce $\alpha$-alumina in sub- and supercritical fluid media (ts : residence time, $\mathrm{pc}$ : critical pressure, Tc : critical temperature). 


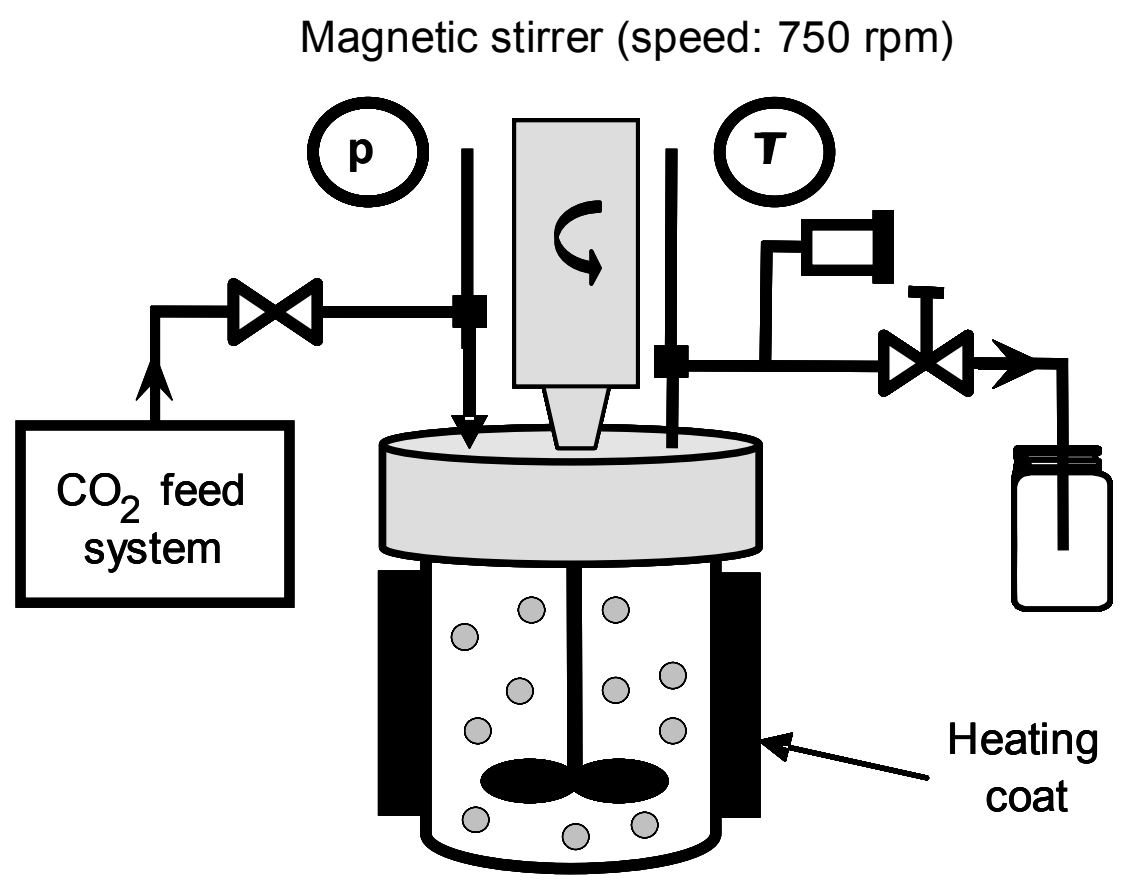

Fig. 2. High pressure, high temperature stirred reactor for material synthesis in supercritical fluids. $\mathrm{T}$ and $\mathrm{p}$ are temperature and pressure controllers, respectively. 


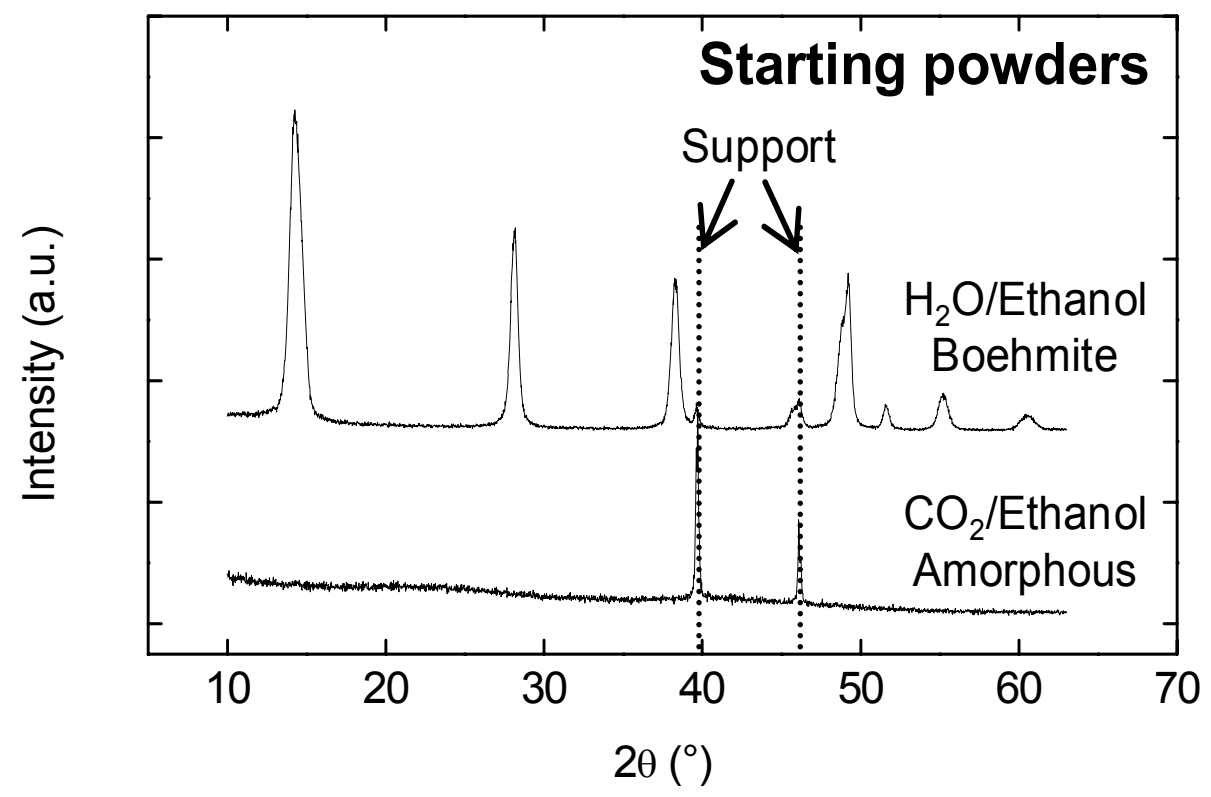

Fig. 3. X-ray patterns of the powders according to the fluid nature used for the nowder sunthesis 

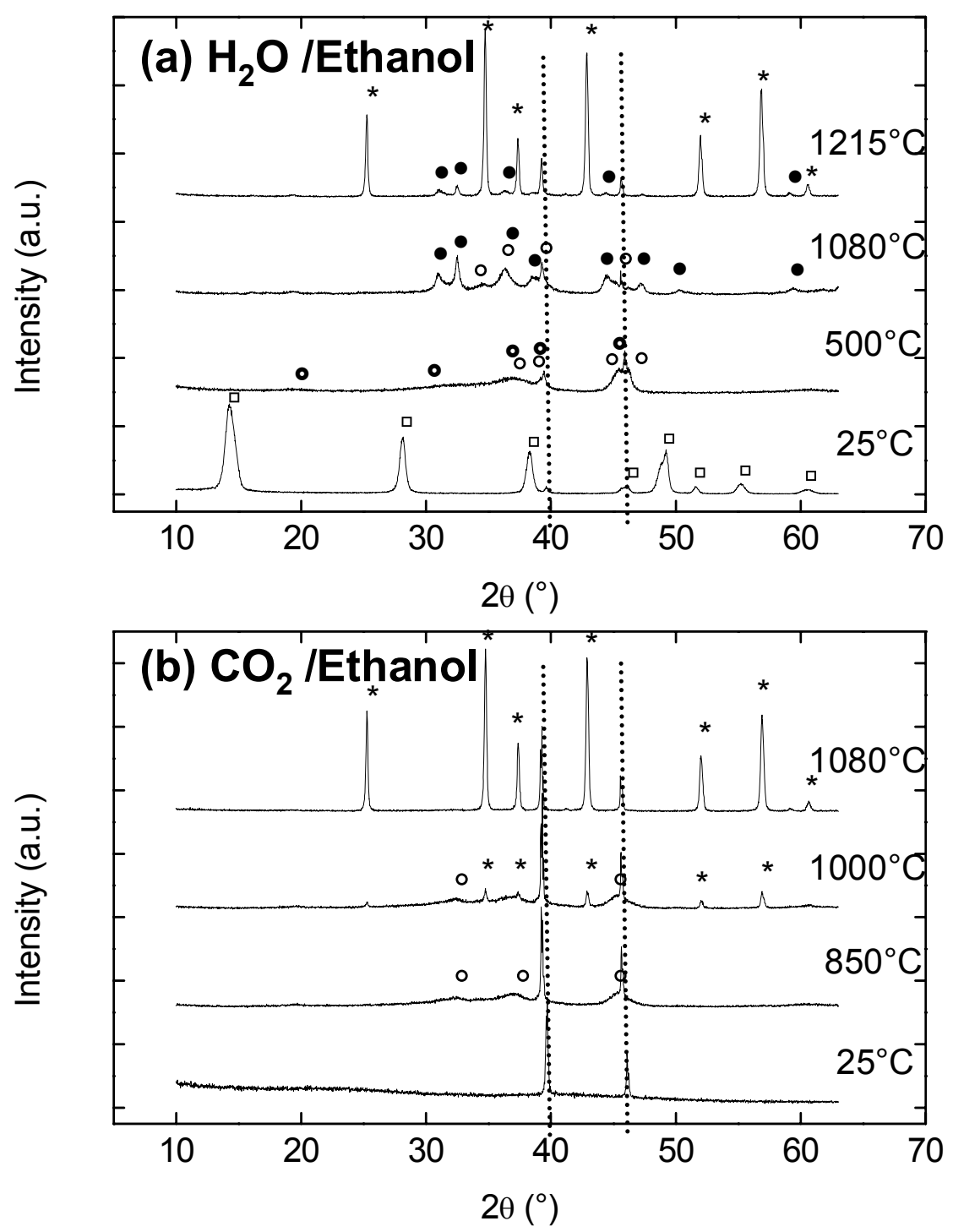

Fig. 4. Structural evolution with temperature of powders synthesized in (a) water/ethanol ( $\square$ boehmite, $\bigcirc \gamma$-alumina, - $\delta$-alumina, $\theta$-alumina and $* \alpha$-alumina) and (b) $\mathrm{CO}_{2} /$ ethanol. ( $\bigcirc \gamma$-alumina, ${ }^{*} \alpha$-alumina $)$. 

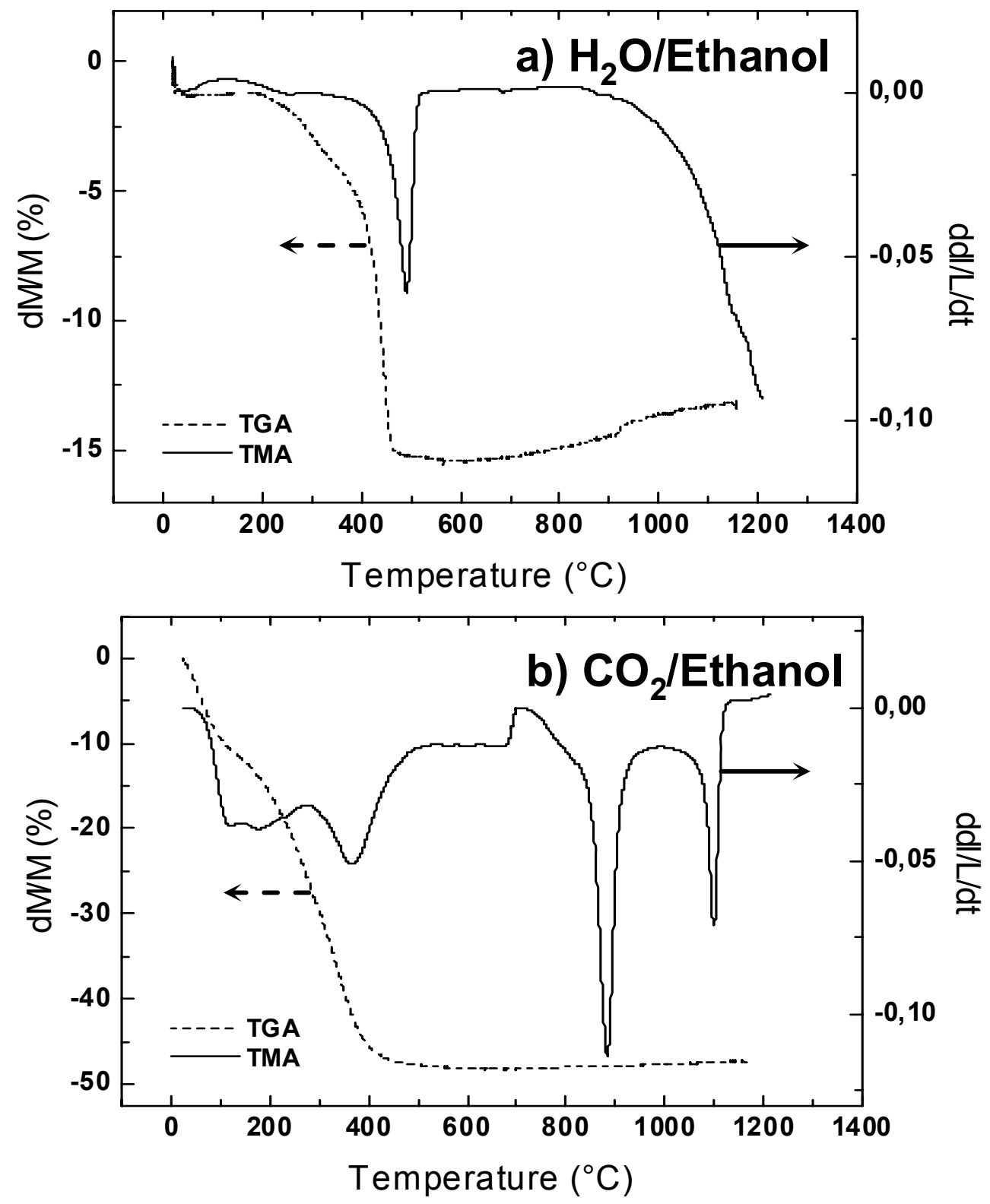

Fig. 5. TMA (shrinkage rate) and TGA for powders obtained in a) water/ethanol b) $\mathrm{CO}_{2}$ /ethanol. TGA ordinate axis is on the left side of the figure.

The derivative of the shrinkage ordinate axis is on the right side of the figure. 


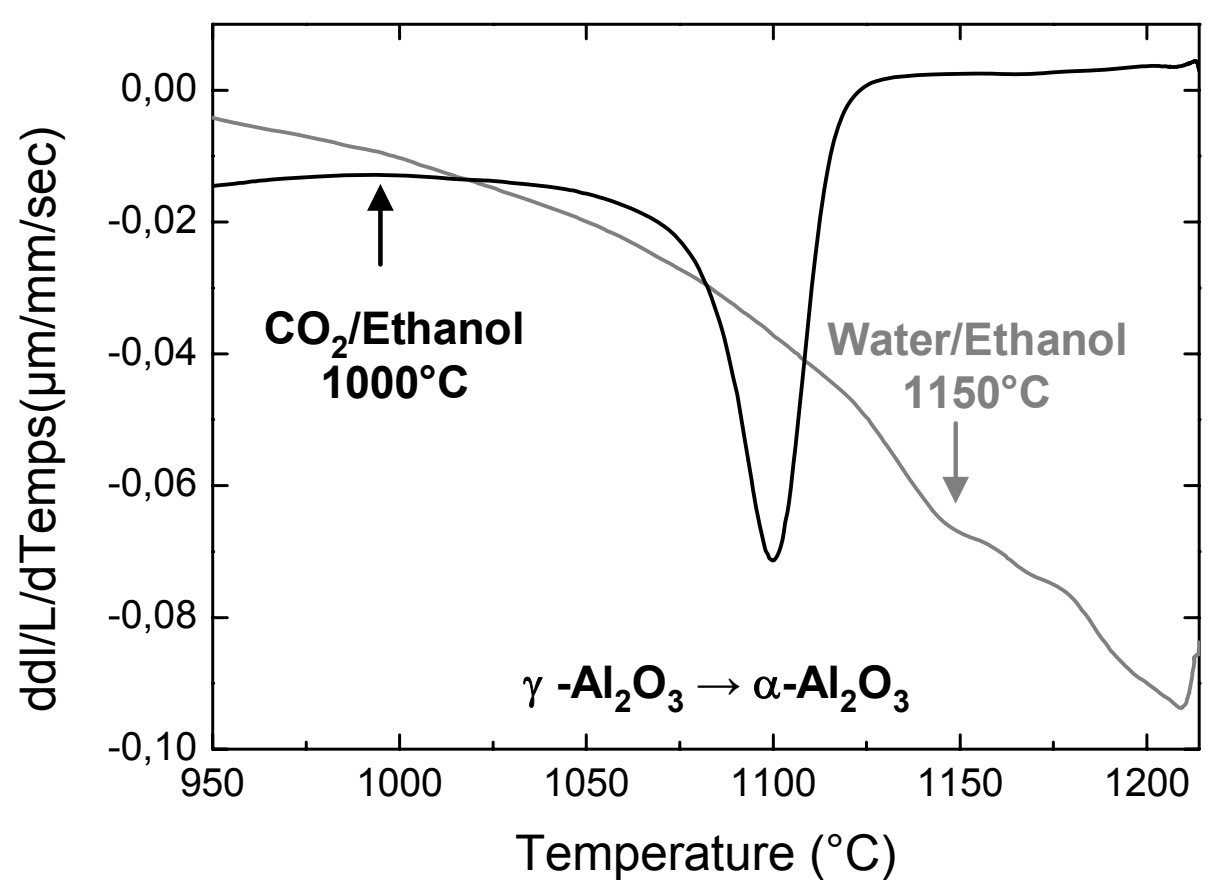

Fig. 6. Shrinkage rate in the temperature range of the $\gamma \rightarrow \alpha$ transition for the two powders. 


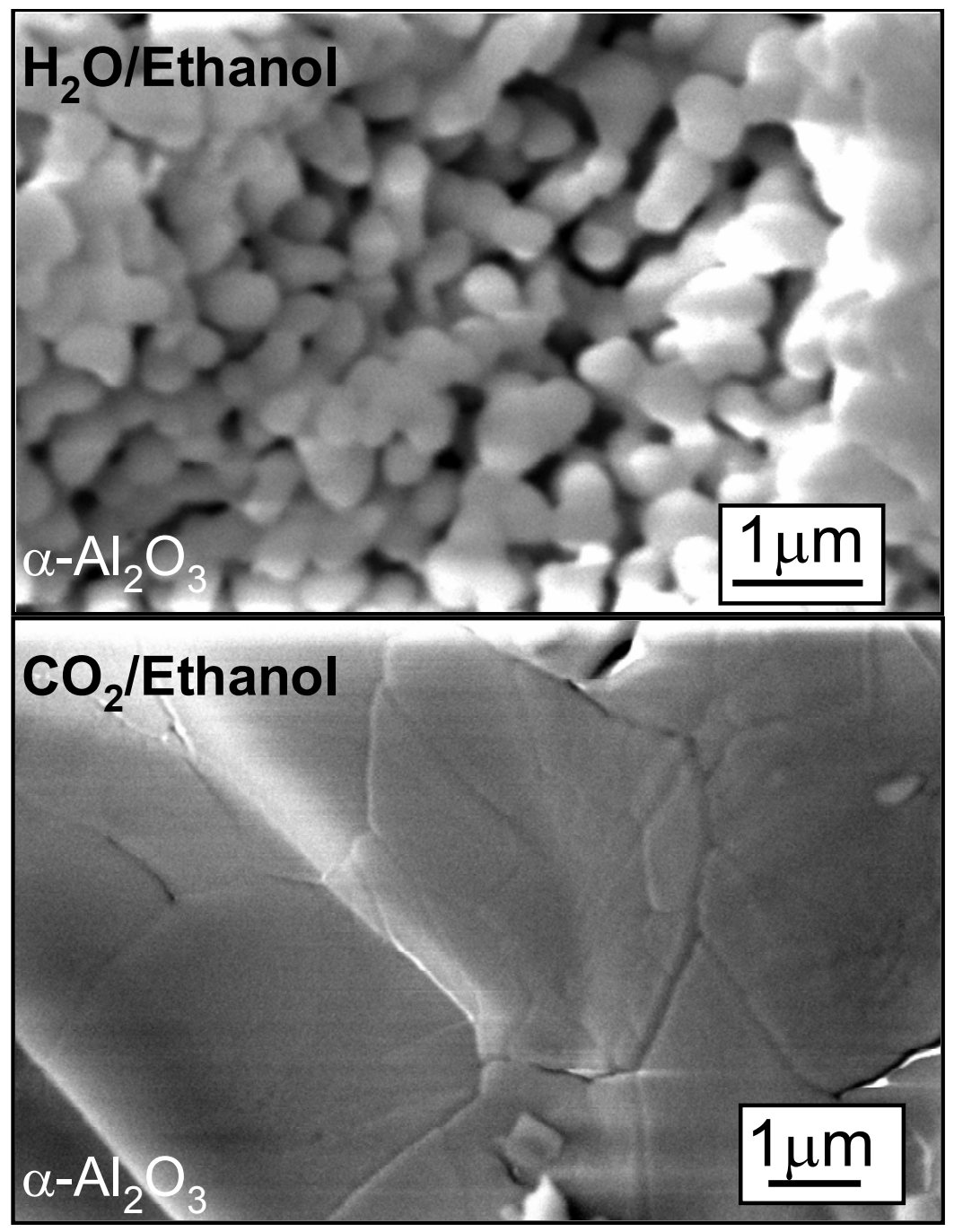

Fig. 7. SEM micrographs of alumina ceramics sintered during $4 \mathrm{~h}$ at $1200^{\circ} \mathrm{C}$ 
(a) Loose packing

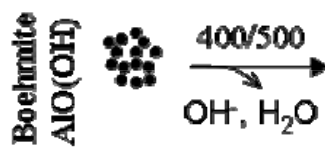

(1) (8)

$800 / 1150$

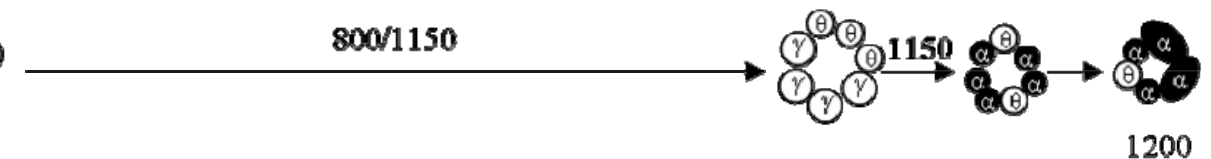

(b) Close packing

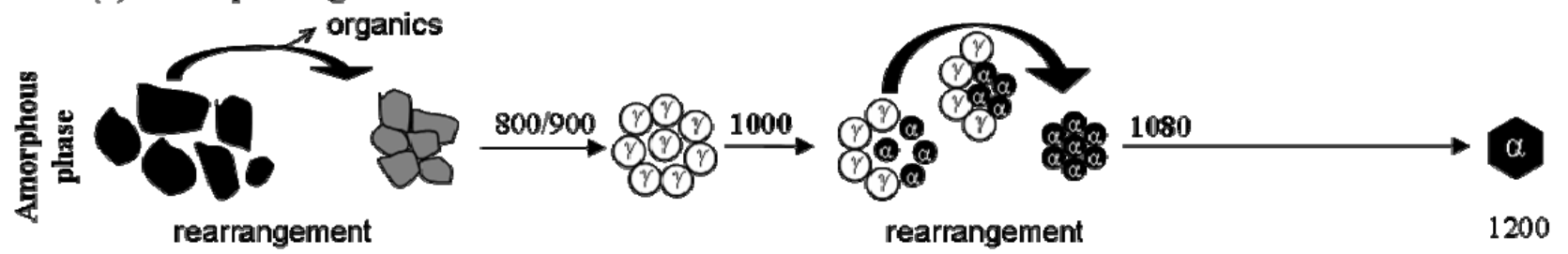

Temperature $\left({ }^{\circ} \mathrm{C}\right)$

Fig. 8. Proposed sintering paths for (a) boehmite obtained in water/ethanol and (b) amorphous alumina synthesised in $\mathrm{CO}_{2} /$ ethanol $^{19}$ 